\title{
Causse de Gramat et causse de Martel
}

\section{(2) OpenEdition \\ Journals}

Édition électronique

URL : http://journals.openedition.org/adlfi/10772

ISSN : 2114-0502

Éditeur

Ministère de la culture

Référence électronique

"Causse de Gramat et causse de Martel », ADLFI. Archéologie de la France - Informations [En ligne], Midi-Pyrénées, mis en ligne le 01 mars 1997, consulté le 02 mai 2019. URL : http://

journals.openedition.org/adlfi/10772

Ce document a été généré automatiquement le 2 mai 2019.

(C) Ministère de la Culture et de la Communication, CNRS 


\section{Causse de Gramat et causse de Martel}

Date de l'opération : 1988 - 1991 (PR)

Inventeur(s) : Girault Jean-Pierre

1 La poursuite de cette opération de prospections-inventaires (Gallia Informations, 1989-1: 171) est à l'origine de nombreuses découvertes restées jusqu'alors inédites ou de réactualisations rendues nécessaires par l'aspect diachronique qui, jusqu'à présent, n'avait pas été mis en évidence. En effet, cette région du nord du Lot était surtout connue par sa richesse en mégalithes. En fait, la recherche en matière de préhistoire a de tout temps occulté l'importance des indices, pourtant bien visibles au sol, des périodes protohistoriques anciennes et récentes, de même que celles se rapportant aux implantations gallo-romaines, médiévales et modernes.

2 Au-delà de la reprise nécessaire des éléments répertoriés, il convenait de prolonger systématiquement l'inventaire en cours et de préciser les références cadastrales, géologiques, dimensionnelles et bibliographiques de l'ensemble des gisements.

Les industries préhistoriques occupent, de façon privilégiée, les bords de vallées marécageuses et se trouvent le plus souvent à proximité immédiate de bancs de silex (Bajocien) comme au Puy d'Issoludà Vayrac, l'Enclause à Strenquels et La Combe des Lacs à Sarrazac, où le silex paraît avoir été exploité durant le Paléolithique moyen (débitage Levallois) et supérieur ainsi qu'au Néolithique.

4 En ce qui concerne les tumulus et les dolmens, la répartition des sites montre des zones à fortes concentrations en rapport avec la nature du sol (couvert humide très mince) qui a interdit toute pratique culturale (secteur du Bathonien inférieur au sud de Martel). Ainsi, on les retrouve généralement implantés à plusieurs centaines de mètres du bord des falaises de la vallée de la Dordogne et, la plupart du temps, sur les pentes douces du plateau. Les «hiatus » d'occupation correspondent aux placages sidérolithiques mais aussi aux secteurs où les dolines sont abondantes. L'absence de vestiges dans des zones de remise en culture ou d'activité agricole ancienne doit être interprétée avec prudence car elle n'est pas due à un choix délibéré mais, au contraire, à des destructions : en 1988, sur 
la zone prospectée, cinquante-trois tumulus et trois dolmens avaient disparu lors de mises en culture.

De 1988 à 1991, soixante-douze dolmens, quatre coffres, dix menhirs et cinq cent dix-sept tumulus ont été inventoriés (treize dolmens, quatre coffres, cinq menhirs et quatre cent cinquante-cinq tumulus sont inédits) et, malheureusement, pour quelques-uns d'entre eux déjà détruits (quatre dolmens et cent un tumulus). Quatorze nécropoles tumulaires ont pu également être identifiées : dix sur Carennac, à La Gavacherie, Les Cerisiers, Le Levat, Le Clos de la Dague, etc.) et deux à Floirac, dont un ensemble de dix-huit tumulus à Escapasse. Dans une dizaine de cas, des structures d'enclos (pierres, dalles plantées, cailloutis) sont associées aux tertres funéraires, leur contemporanéité étant assurée par la superposition de tumulus sur leur tracé (par exemple, à Carennac, Les Cerisierset Le Clos de la Dague; de même qu'aux Parties où un enclos en pierre sèche entoure un ensemble composé de trois tumulus et un dolmen). En revanche, à Martel (Les Mayrières) un habitat du Premier Âge du fer est situé sur les marges d'une nécropole tumulaire [ (Fig. $\mathrm{n}^{\circ}$ 1 : Nécropole tumulaire) et (Fig. $\mathrm{n}^{\circ} 2$ : Nécropole tumulaire)].Trente-sept sites galloromains dont vingt-trois inédits ont pu être recensés et sont matérialisés au sol par l'abondance des éléments de construction et de tegulae, comme aux Teullières (Vayrac) ou à La Borie Grande (Condat). Parallèlement, plusieurs centaines de cabanes en pierre sèche ont fait l'objet de relevés topographiques systématiques, enrichis en 1991 par le recensement de deux cent cinquante-neuf croix de chemin.

6 Les résultats acquis sont considérables puisque se sont plus de douze menhirs, soixantedix-neuf dolmens, huit coffres, mille quatre-vingt-trois tumulus, etc., qui ont été répertoriés, relevés et inclus dans la « carte archéologique » du département du Lot.

\section{ANNEXES}


Fig. $\mathrm{n}^{\circ} 1$ : Nécropole tumulaire

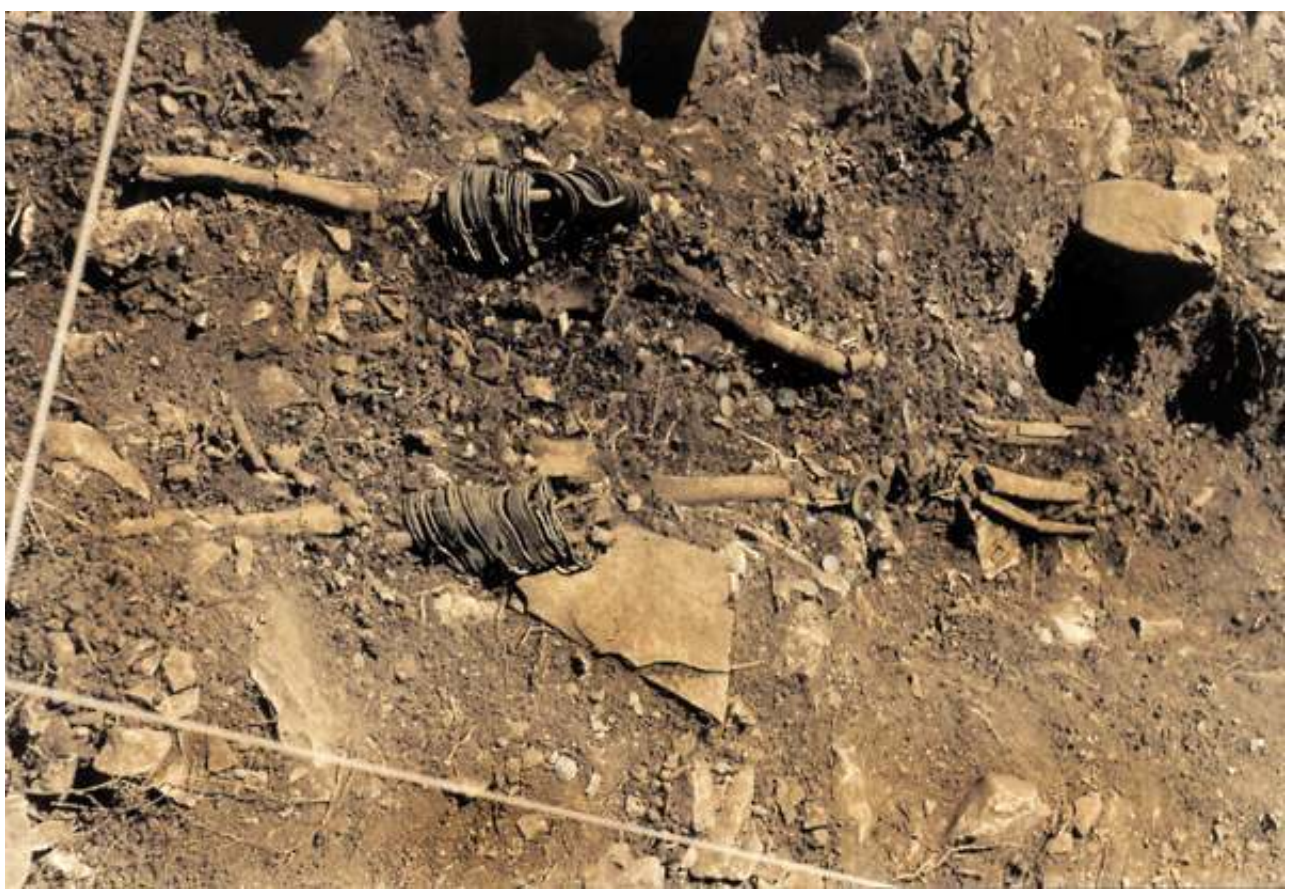

Auteur(s) : Vernet, Jean-Louis. Crédits : Gi 1997 ; CNRS Éditions 1998 (1991)

Fig. $n^{\circ} 2$ : Nécropole tumulaire

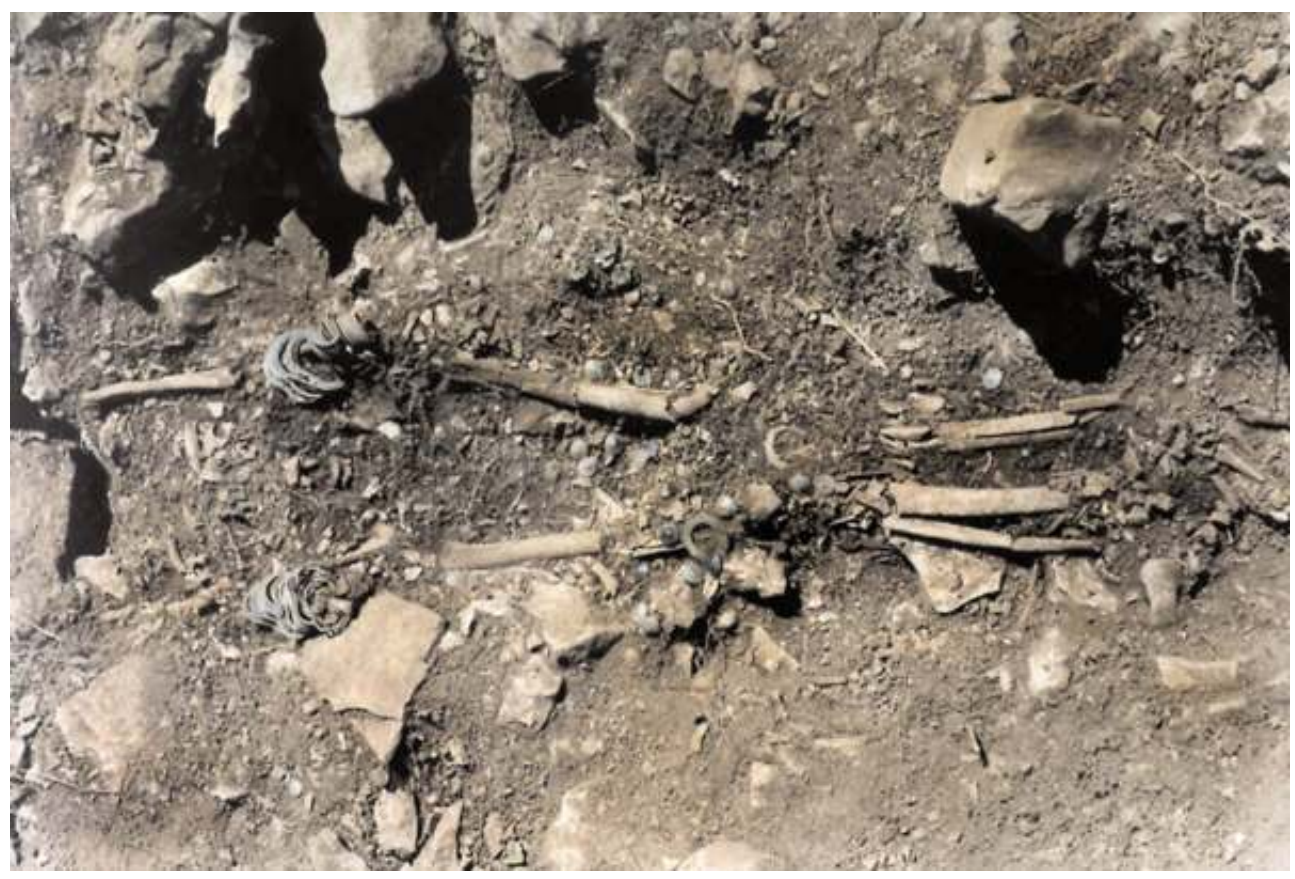

Auteur(s) : Vernet, Jean-Louis. Crédits : GI 1997 ; CNRS Éditions 1998 (1991) 
INDEX

Index chronologique : âge du Bronze, Antiquité romaine, Néolithique, Paléolithique, Premier âge du Fer

operation Prospection (PR) 